\title{
Nanocomposite for Rapid Prototyped Complete Denture Eighteen months follow-up on clinical performance
}

\author{
CORINA MARILENA CRISTACHE ${ }^{1 \#}$, EUGENIA EFTIMIE TOTU²*\#, ALEXANDRA RALUCA GROSU², OANA ENE²,3, \\ IRINA ADRIANA BEURAN" ${ }^{4 *}$ MIHAI BURLIBASA ${ }^{1 *}$ \\ ${ }^{1}$ Carol Davila University of Medicine and Pharmacy, Faculty of Midwifery and Medical Assisting (FMAM), Department of Dental \\ Techniques, 8 Eroilor Sanitari Blvd, 050474 Bucharest, Romania \\ 2University Politehnica of Bucharest, Faculty of Applied Chemistry and Material Science,1-5 Polizu Str., 11061 Bucharest, Romania \\ ${ }^{3}$ Megagen Dental Implant SRL, 38 Delea Noua Str, 030925, Bucharest, Romania \\ ${ }^{4}$ Carol Davila University of Medicine and Pharmacy, Faculty of Dental Medicine,17-23 Calea Plevnei, 0010221, Bucharest, Romania
}

\begin{abstract}
The aim of the present study was to evidence the improved behavior of our modified PMMA-TiO, nanocomposite material used to obtain 3D printed complete dentures. A protocol for long-term rapid prototyping complete denture manufacturing using our nanocomposite material, completely characterized and the evaluation of the clinical performance and complications after eighteen months of continuous wearing was also described. Thirty-five fully edentulous patients were enrolled in this prospective clinical study and forty-five complete dentures (31 maxillary and 14 mandibular) have been obtained using an additive manufacturing technology. Due to the good performances of the nanocomposite material, no major functional complications for the obtained medical devices occurred and the clinical outcomes for the 3D printed dentures were favorable evaluated at eighteen months follow up.
\end{abstract}

Keywords: hybrid nanocomposite, $\mathrm{PMMA}-\mathrm{TiO}_{2^{\prime}}$ complete denture, rapid prototyping, clinical trial

Heat-cured poly(methyl methacrylate) (PMMA) materials are the mostly used in manufacturing dentures with the conventional workflow. However, there are several problems related to this material, such as: polymerization shrinkage leading to reduced fit between the denture bearing tissues and the base, lack of dimensional stability, increased content of residual monomers, tendency to absorption of water, changeability of color and high porosity, harboring microorganisms such as Candida albicans, especially on the intaglio surface [1]. The conventional method of fabricating complete removable dentures, introduced for over 80 years, remained relatively stable, effective and reliable since then [2]. Nevertheless, it is difficult to reach the quality for the conventional fabrication method, as it requires experienced prosthodontists or general dentists, skilled dental technicians, and patient's numerous office visits. To overcome these drawbacks, new materials and Computer-aided design and computer-aided manufacturing (CAD/CAM) technique has been introduced for designing and fabricating complete dentures, either by a subtractive (milling) manufacturing or additive manufacturing, (rapid prototyping - RP). The subtractive manufacturing uses a computerized numerical control (CNC) machine to produce a physical model from solid block materials such as metal, resin, or zirconia, been associated with dentistry, especially in the fabrication of dental crown copings and frameworks for bridge restoration [3]. Additive manufacturing or 3D printing is a process by which materials are joined layer by layer to produce models based on computerized threedimensional (3D) data [4,5]. For the digital fabrication of removable complete dental prostheses, several digital denture systems such as DENTCA/Whole You CAD/CAM system (Dentca Inc., Los Angeles, USA), AvaDent digital dentures (Global Dental Science LLC, Scottsdale, Arizona, USA), Pala Digital Dentures (Heraeus Kulzer, Hanau, Germany), etc., are currently available. Among them, Dentca, and Pala systems uses the additive manufacturing to fabricate a trial denture [6]; some other systems, as
AvaDent, utilize milling process from a pre-polymerized resin block for the denture base production [7]. To date, rapid prototyped dentures have been used only as try-in dentures [8-11] or for outer shells (cameo/occlusal surface and intaglio/tissue surface) fabrication (using 3D laser lithography) and a complete denture from photo polymerized composite resin material [12].

Lately, nanotechnology has been extensively applied in dentistry. The used nanofillers could be obtained through different methods, such are sol-gel processes [13]. Due to the small dimensions of the nanosized particles, the overall additive level is increased. The nanocomposites for dental usage comprise both nanohybrid and nanofilled structured materials. The later contain nanofiller clusters and dispersed nanofillers besides some other additives as nano/ micro silica. Clinical studies became important in order to validate in clinical environment the behavior and performances of the 3D printed complete dentures based on the new nanocomposites. No previous studies presented long-term assessment of 3D printed dentures in clinical environment.

Therefore, the first objective of the present study was to evaluate the clinical performance of the nanohybrid composite that we developed. A protocol for long-term rapid prototyping complete denture manufacturing using the improved PMMA-TiO, nanocomposite material, completely characterized [14-17] and the evaluation of the clinical performance and complications after eighteen months of continuous wearing was also performed.

\section{Experimental part \\ Materials}

The nanoparticles used for nanocomposite preparation were $\mathrm{TiO}_{2}$ (anatase variety) from Aldrich (Merck KGaA, Darmstadt, Germany). According to the procedure introduced by us elsewhere [18], the nanotitania particles have been functionalized with methacrylic acid (Aldrich) in order to secure the link between nanoparticles and the poly(methacrylate) backbone. Subsequently, these 


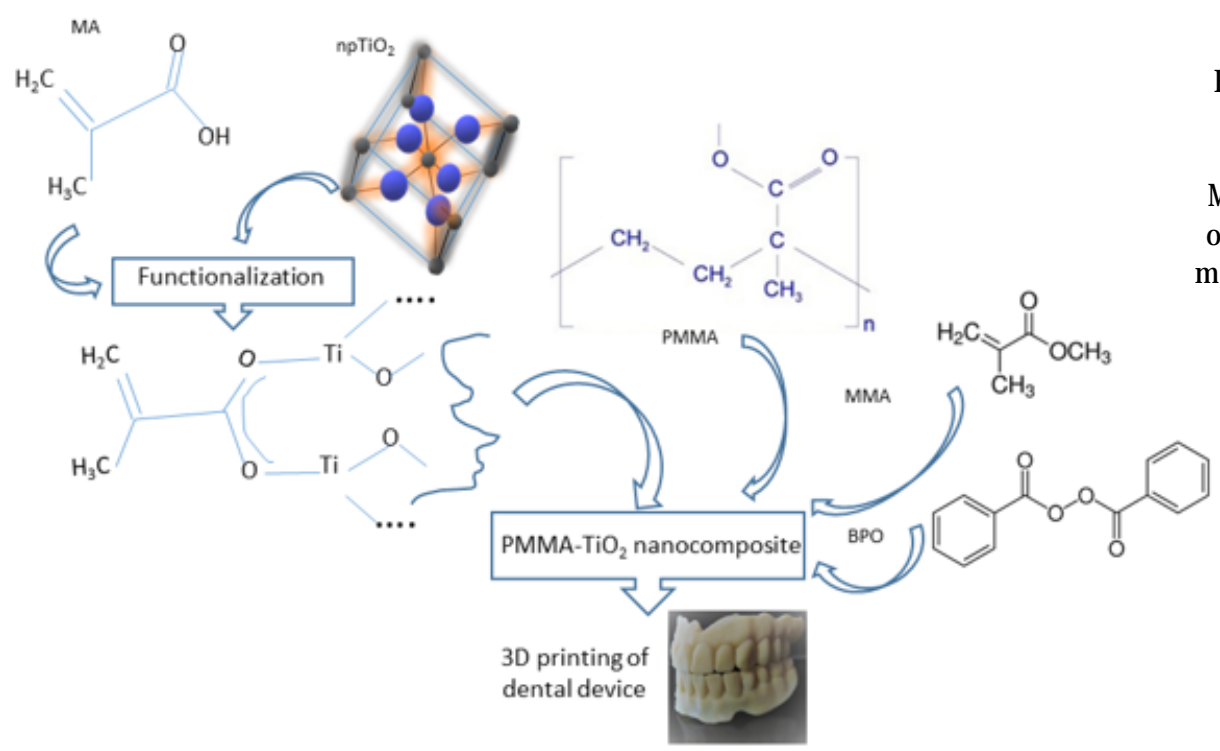

Fig. 1. Schematic representation of the main stages applied to obtain the 3D printed complete dental prosthesis. MA - methacrylic acid; $n p T_{i O}$ - titanium oxide nanoparticle; PMMA - poly(methyl methacrylate); MMA- methyl methacrylate (monomer); BPO - benzoyl peroxide.

functionalized nanosized particles were added in appropriate amount $(0.4 \% \mathrm{wt})$ under permanent and vigorouslystirring to a homogenized mixture of poly (methyl methacrylate) with methyl methacrylate monomer (3:1) and initiator - peroxide benzoyl (1\%) (EnvisonTec, $\mathrm{GmbH}$, Gladbeck, Germany). After its preparation, the hybrid mixture has been sonicated for $4 \mathrm{~h}$. The material prepared in this manner has been completely characterized: physically, chemically and biochemically, as presented elsewhere [13,14,16-18].

Then, the complex nanocomposite was used to manufacture the 3D printed complete dental prosthesis. The overall procedure applied to obtain finally the 3D printed complete denture using the nanocomposite material could be followed in the scheme presented in figure 1.

The structural analysis of the complex material was performed on an INSPECT-F50 FEl (Thermo Fisher Scientific, Hillsboro, OR, USA) equipment. The elemental mapping was done, as well.

The complete dentures were manufactured by rapid prototyping technique, using the described hybrid nanocomposite.

\section{Materials and Methods applied for clinical evaluation}

Thirty-five fully edentulous patients were enrolled in this prospective clinical study (Bioethical Committee approval no. 98/2016, ClinicalTrials.govldentifier:NCT02911038). Accepted patients had to meet the following inclusion criteria:

-18 years or older with mental capacity and legal competence;

-Complete edentulism in the maxilla and/or mandible with conventional denture need to be replaced;

-Class I to III according to American College of Prosthodontists Classification of Complete Edentulism [19];

-Patients with good systemic health, able to attend all the follow-up sessions;

-Patients agreeing to wear CAD/CAM 3Dprinted complete dentures.

Patients not willing to wear removable dental restorations or refusing the participation in the study were excluded.

A partially digital workflow with the sequence presented in figure 2 has been performed.

In the data collection appointment, after informed consent signed by the patient, information regarding

medical and dental history, demographics and current medications, were collected and completed. A set of intraoral and extra oral photographs were taken. Oral soft and hard tissue examination was performed and preliminary impressions in stock trays, using fast set alginate was taken to be used for custom trays with occlusal rim fabrication.

In the dental laboratory, preliminary impressions were poured in Elite Model (Zhermack SpA, Badia Polesine, Italy). The casts were used to fabricate custom acrylic trays using light-cured custom tray material, Plaque Photo ${ }^{\circledR}$ (Willmann \& Pein GmbH, Barmstedt, Germany) and occlusal rims were made using baseplate wax.

In the first clinical appointment, border molding of the custom trays was done and functional impressions of maxillary and mandibular arches were completed using Ex-3-N Gold thermoplastic wax (Johannes Meist Dentalfabrikation, Feuchtwangen, Germany).

Subsequently, in the dental laboratory, after specific procedures, all data were digitalized and the mounted casts were transferred in a virtual articulator. Complete denture design were performed in 3Shape software (Copenhagen, Denmark). The digital preview of the teeth set-up of complete dentures from the laboratory was reviewed, necessary changes were performed and relevant screenshot were sent to the patient via social media (email, WhatsApp, Facebook messenger) for approval. After the final approval, the fabrication of the monolithic denture was completed by the laboratory.

A $0.4 \% \mathrm{TiO}_{2}$ nanoparticles reinforced PMMA composite obtained according to the previously presented procedure with low adherence of microbial factors [13] and improved mechanical strength, was used according to an additive manufacturing technology, Digital Light Projection Manufacturing (DLPM), using EnvisonTEC Perfactory® 3D printer.

As mentioned in the above section, the PMMA - $\mathrm{TiO}_{2}$ nanocomposite preparation and the detailed workflow for obtaining the stereolitographic complete dentures have been described elsewhere [13].

For denture aesthetic, adjustments and customized pink gingiva, light-cured Crea.lign veneering system, (Bredent, Senden, Germany) was applied on denture teeth and cameo surface (fig. 3).

In the second clinical appointment, the fabricated dentures were carefully examined prior to delivery. At denture insertion, the border and intaglio surfaces of the dentures were checked, necessary occlusal adjustments 


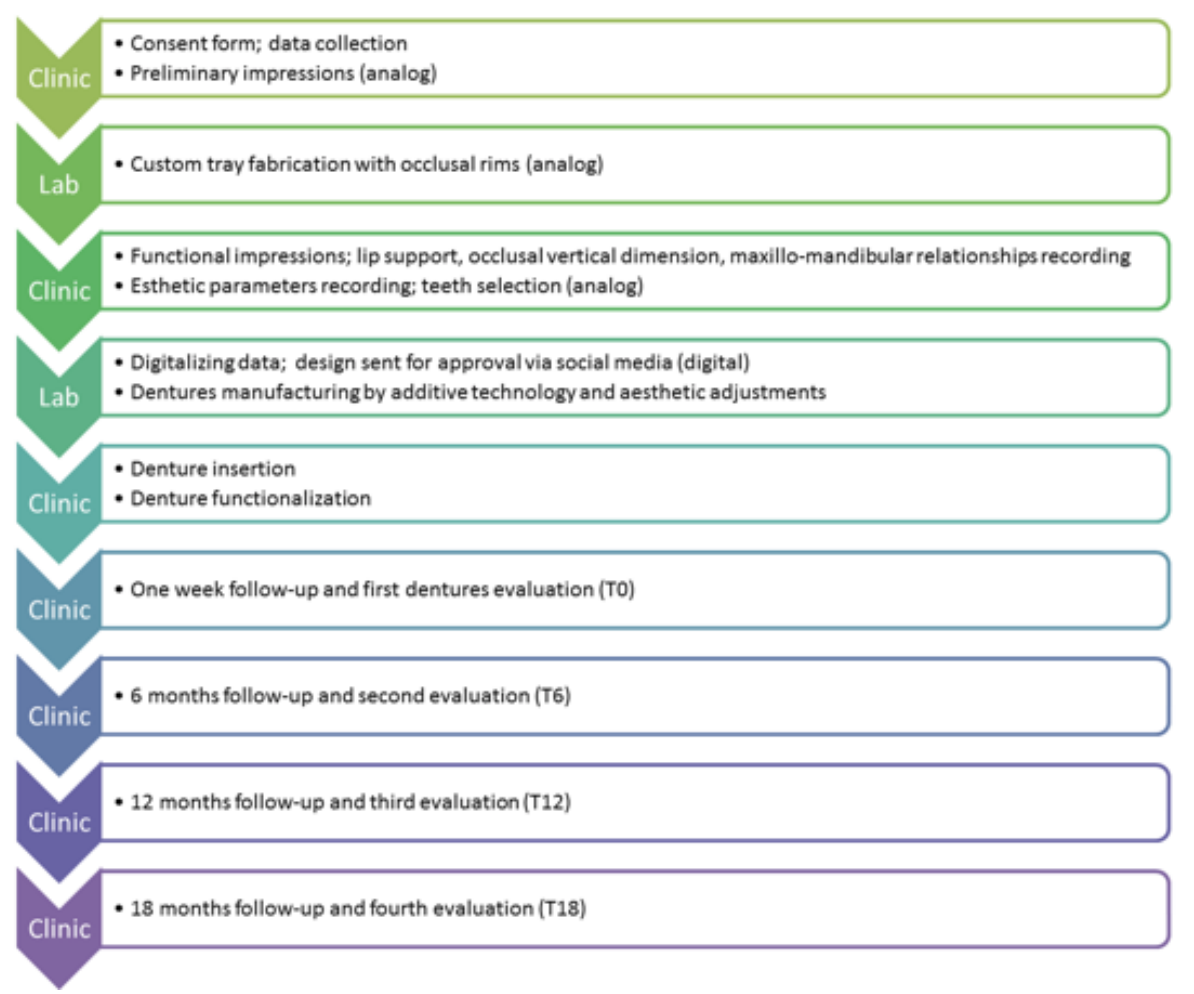

Fig. 2. Partially digital workflow for complete dentures manufacturing and follow-up sequences

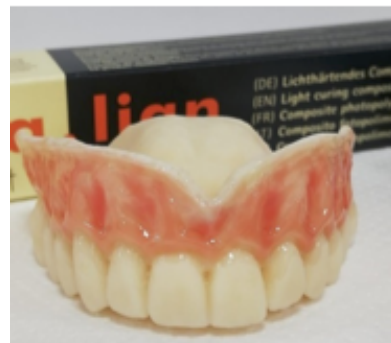

Fig. 3. Aesthetic denture adjustment

Table 1

THE MODIFIED KAPUR INDEX (MKI) USED FOR RETENTION AND STABILITY EVALUATION [21]

\begin{tabular}{|c|c|c|}
\hline Score & Retention & Stability \\
\hline 5 & $\begin{array}{l}\text { Excellent: When a denture offers excellent resistance to } \\
\text { vertical pull and lateral force. }\end{array}$ & N/A \\
\hline 4 & $\begin{array}{l}\text { Very good: When a denture offers very good resistance } \\
\text { to vertical pull and lateral force. }\end{array}$ & $\begin{array}{l}\text { Excellent: When a denture offers excellent stability, } \\
\text { demonstrates no rocking on its supporting structures } \\
\text { under pressure. }\end{array}$ \\
\hline 3 & $\begin{array}{l}\text { Good: When a denture offers moderate resistance to } \\
\text { vertical pull and lateral force. }\end{array}$ & $\begin{array}{l}\text { Good: When a denture offers good stability, } \\
\text { demonstrates very slight rocking on its supporting } \\
\text { structures under pressure. }\end{array}$ \\
\hline 2 & $\begin{array}{l}\text { Fair: When a denture offers resistance to vertical pull } \\
\text { and lateral force }\end{array}$ & $\begin{array}{l}\text { Fair: When a denture offers sufficient stability, } \\
\text { demonstrate slight rocking on its supporting structures } \\
\text { under pressure. }\end{array}$ \\
\hline 1 & $\begin{array}{l}\text { Poor: When a denture offers moderate resistance to } \\
\text { vertical pull and little or no resistance to lateral force. }\end{array}$ & $\begin{array}{l}\text { Poor: Some stability, demonstrate moderate stability on } \\
\text { its supporting structures under pressure. }\end{array}$ \\
\hline 0 & $\begin{array}{l}\text { No retention: When a denture seated in its place } \\
\text { displaces itself. }\end{array}$ & $\begin{array}{l}\text { No stability: When a denture base demonstrate extreme } \\
\text { rocking on its supporting structures under pressure. }\end{array}$ \\
\hline
\end{tabular}
denture $=$ sum score of 5-7; Clinically very good denture $=$ sum score of $>7$

were performed and, function and phonetics of the complete dentures was evaluated. Denture care instructions were provided. This procedure was repeated at $24 \mathrm{~h}$ and one week after denture insertion.

Clinical evaluations of retention and stability of complete dentures were performed at one week, six months, twelve month and eighteen month post denture insertion by two experienced prosthodontists using the modified Kapur index (MKI) (table1) [20,21]. The lowest score value was considered. If scores differences were more than 1 point, a third evaluator solved any disagreement. Maxillary and mandibular dentures were scored separately for retention and stability criteria, also, the retention and stability scores of each maxillary and/or mandibular dentures were summed and, based on scores, dentures were classified as excellent, good and poor. The total number of post insertion adjustment visits (unscheduled), and any reported complications were assessed and recorded by a single examiner (CMC) to avoid inter-examiner variability.

Clinically good denture $=$ sum score of 5-7; Clinically very good denture $=$ sum score of $>7$
Statistical analyses were performed using XLSTAT 2014 (Addinsoft, New York, NY, USA). Changes of Kapur modified index after treatment and over time was investigated using the Mann-Whitney U test. A p value $<0.05$ was considered significant.

\section{Results and discussions}

A $0.4 \% \mathrm{TiO}_{\text {- }}$-poly(methyl methacrylate) nanocomposite has been obtained. It exhibits good biocompatibility [14,22] and excellent structural, electrical, thermal and specific performances [16-18].

The homogeneity of the nanocomposite material resulted from the SEM analysis of specimen morphology is presented in figure 4 . The elemental mapping showed the uniform distribution of Ti into the polymeric matrix. Therefore, we could concluded that the functionalization of $\mathrm{TiO}_{2}$ nanoparticles with methacrylic acid, before their addition to the polymeric mixture, has been beneficial for the overall behavior of the hybrid material.

The morphology of the nanocomposite which has been completed with FT-IR and Raman spectroscopy analysis 
a

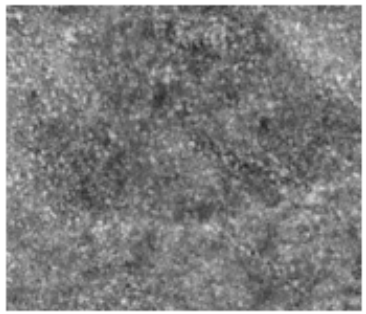

b

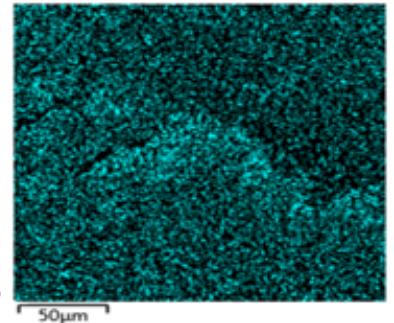

$[13,16]$, putting in evidence the presence of the specific functional groups $[22,23]$, supports the conclusion that the obtained nanocomposite material could be successfully use for 3D printing technique.

The thermal behavior [18] of the composite material based on PMMA improved with the added filler (TiO nanoparticles), comply with the phase transformation of the polymeric matrix due to the supplementary additives [24]. Other characteristics, namely, the electrical behavior [16], interpreted according to specific electrochemical impedance answer [25], showed that the proposed material is suitable for usage as dental device.

\section{Results of the clinical study}

A total of thirty-five patients aged 48 to 81 years old, mean age 64.26 ( \pm 8.27 ) years old, twenty-three female, were enrolled in this study. No patients were lost to followup. Patients' characteristics are presented in figure 5 and figure 6 .

A total of 45 complete edentulous arches ( 31 maxillary and 14 mandibular) have been restored with rapid
Fig. 4. Morphology of $\mathrm{TiO}_{2}$ - PMMA nanocomposite. a. SEM image; b. Elemental mapping - Ti presence (TiK $\alpha 1$ ).

prototyped dentures. $5.16 \%$ of the restored maxillary arches and $43 \%$ of the mandibular arches had verylittle supporting structures described by the ACP classification of class III (fig.6). The retention and stability evaluation of conventional dentures, before treatment, revealed poor maxillary and mandibular dentures (total modified Kapur score $\leq 3$ ) as shown in figure 7.

For the maxillary dentures, at the first evaluation post dentures insertion, a statistically significant improvement in retention and stability was observed $(p<0.05)$. The maxillary MKI post insertion scored between 5 and 9, meaning good and very good dentures, with good and very good retention and stability. The obtained characteristics were maintained at 18 months follow-up with little or no changes (fig. 8), $p=0.38(>0.05)$.

A significant improvement in dentures retention and stability was noticed for mandibular detures, as well $(p=0.0129,<0.05)$. However, MKI post insertion between 3 and 5 , with a mean of $4.9(S D=0.61)$. The obtained result was mainained during the all follow-up period (fig. 9). Only 5 dentures out of 14 were classified as good considering the retention and stability criteria. For atrophic mandibular
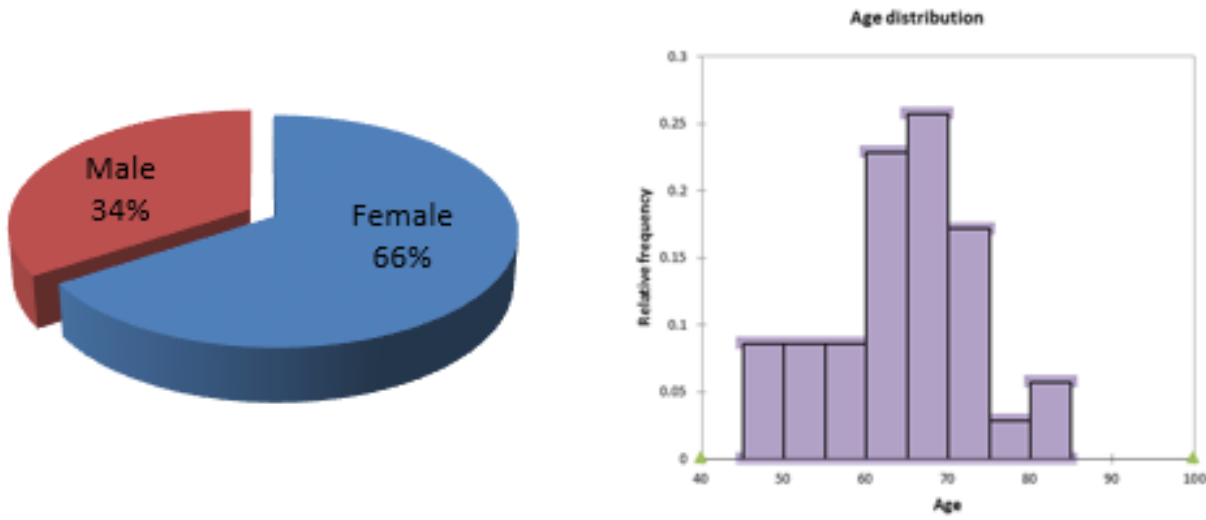

Fig. 5 Gender and age distribution of the enroled patients
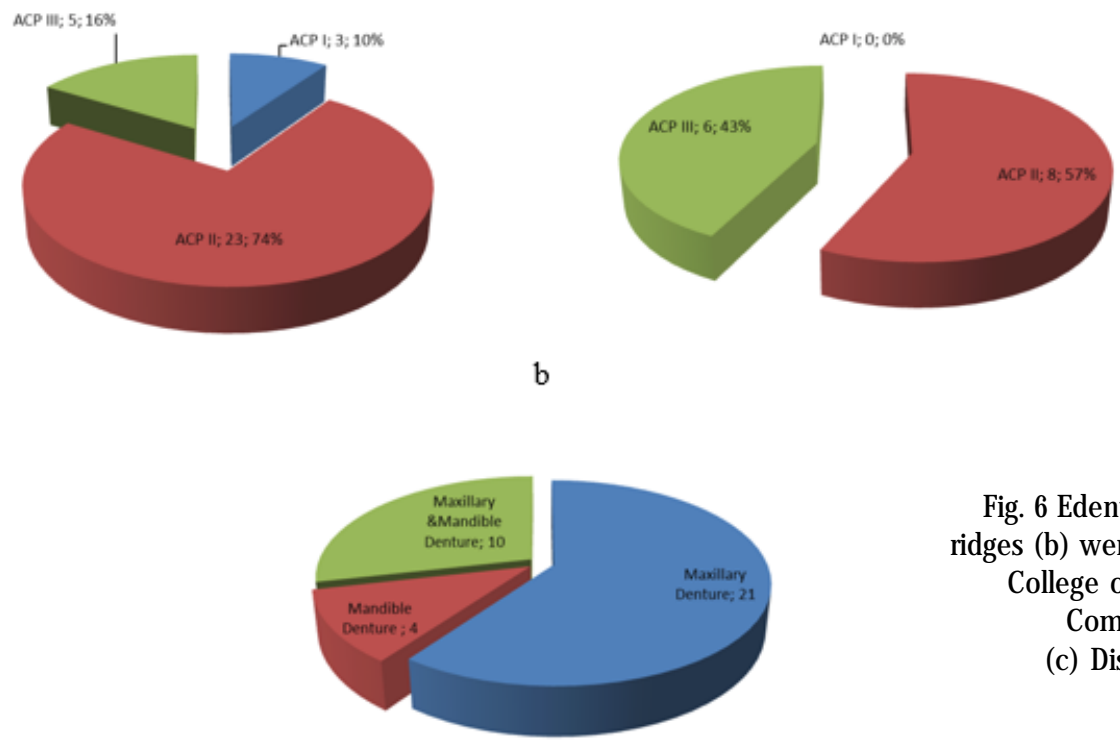

Fig. 6 Edentulous maxillary (a) and mandibular ridges (b) were clasiffied according to the American College of Prosthodontists Classification of Complete Edentulism (ACP) [19].

(C) Distribution of edentulous arches 


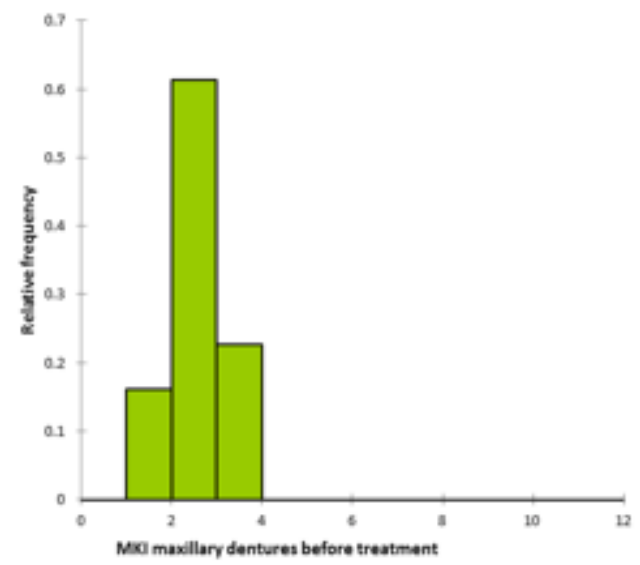

a

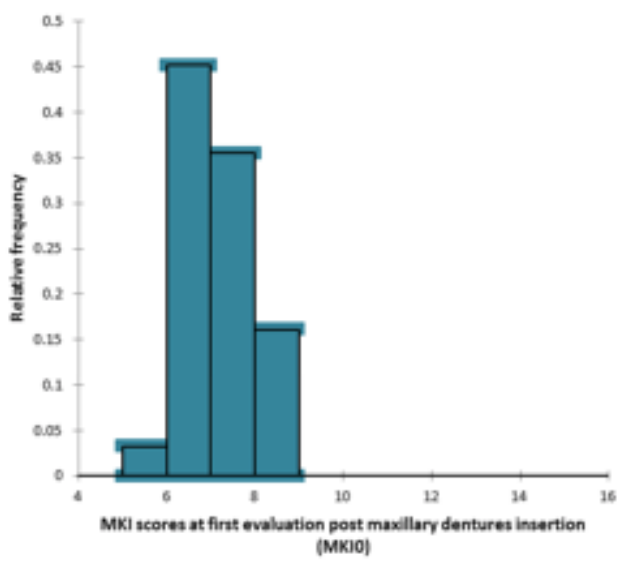

a

Fig. 8 (a). Distribution of MKI scores for maxillary dentures at the first evaluation post denture insertion. (b). Mean and standard deviation of MKI scores with the old dentures, post rapid prototyped dentures insertion (MKIO - at one week post insertion) and during the follow-up evaluations at 6 months (MKI6), 12 months (MKI12) and 18 months (MKI18)

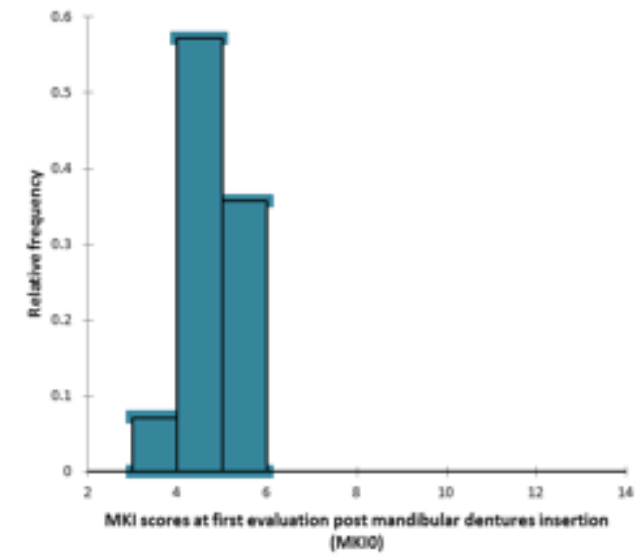

a

Fig. 9 (a). Distribution of MKI scores for mandibular dentures at the first evaluation post denture insertion. (b). Mean and standard deviation of MKI scores with the old dentures, post rapid prototyped dentures insertion (MKIO - at one week post insertion) and during the follow-up evaluations at 6 months (MKI6), 12 months (MKI12) and 18 months (MKI18)

ridges, an implant supported overdenture is mandatory for improving retention and stability [26-28].

An average of 3.06 denture adjustments (unscheduled visits) were needed after insertion ( $S D \pm 0.56)$, during the eighteen months period. Two dentures were accidentally broken and reprinted using the stl. files at the dental laboratory, without any other preliminary clinical appointment.
Even if there were no significantfunctional complications after 18 months of dentures' wearing, a reduction in retention and stability occurred after 18 month due to physiologic continuous bone resorption after teeth loss.

Moreover, Hwang and co-workers, evaluating, in vitro, the trueness and tissue surface adaptation of CAD/CAM mandibular denture bases manufactured using digital light processing and milling found comparable tissue adaptation of digital light processing dentures to the milled denture base [29]. 


\section{Conclusions}

The recently introduced rapid prototyping method for dentures has numerous advantages including reduced clinical chair time (2-3 appointments) for denture fabrication and placement; the ability to provide a replacement or a spare prosthesis by using the stored digital data; high strength; elimination of the in-house laboratory work time and reducing the technician's workload [24]. A major disadvantage for milling technique is the expensive materials used, increasing laboratory cost compared with those for conventional methods. The presented additive manufacturing technique reduces considerably the laboratory cost and complex shapes with high accuracy cam be performed.

The presented partially digital workflow for complete dentures manufacturing is clinically feasible and prosthetic removable devices that metthe clinical requirements could be predictably fabricated. No major functional complications have been observed after 18 months of continuous wearing.

The 3D printed dentures based on PMMA-TiO nanomaterial that have been investigated showed acceptable clinical performance [30] after 18 months of permanent wearing of the medical devices. We consider that continuous reevaluations are requested for a more detailed long-term analysis of the complete dentures 3D printed from our proposed nanocomposites.

Acknowledgement: This work was supported by a grant of the Romanian National Authority for Scientific Research and Innovation, CCCDI - UEFISCDI, project number 30/2016 (ERA-NET-MANUNET II) PRIDENTPRO within PNCDI III.

\section{References}

1.BETTENCOURT, A. F., NEVES, C. B., DE ALMEIDA, M. S., PINHEIRO, L. M., OLIVEIRA, S. A., LOPES, L. P., CASTRO, M. F., Dent Mater, 26, e171-80, 2010.

2. WIMMER, T., GALLUS, K., EICHBERGER, M., STAWARCZYK, B., J. Prosthet. Dent., 115, 2016, p.541.

3. DAW OOD, A., MARTI, B., SAURET-JACKSON, V., DARWOOD, Br Dent J, 219, 2015, p. 521.

4. CRISTACHE, C. M., GROSU, A. R., CRISTACHE, G., DIDILESCU, A. C., TOTU, E. E., Mat. Plast., 55, no.4, 2018, p.555.

5. GUO, N., LEU, M. C., Front. Mech. Eng., 8, No.3, 2013, p. 215.

6. ANDREESCU, C. F., GHERGIC, D. L., BOTOACA, O., HANCU, V., BANATEANU, A. M.; PATROI, D., 55, no. 1, 2018, p.124.

7. STEINMASSL, P. A., KLAUNZER, F., STEINMASSL, O., DUMFAHRT, H., GRUNERT, I., Int. J. Prosthodont., 30, no.2, 2017, p.116.

8. KATTADIYIL, M. T., GOODACRE, C. J., BABA, N. Z., J Calif Dent Assoc, 41, 2013, p.407.

9. KATTADIYIL, M. T., ALHELAL, A., J. Prosthet. Dent., 111, no.4, 2016, p.478.
10.KATTADIYIL, M. T., JEKKI, R., GOODACRE, C. J., BABA, N. Z., J. Prosthet. Dent., 114, 2017, p.818.

11.KATTADIYIL, M. T., ALHELAL, A., GOODACRE, B. J., J. Prosthet. Dent., 117, no.6, 2017, p.721.

12.MAEDA, Y., MINOURA, M., TSUTSUMI, S., OKADA, M., NOKUBI, T. A., Int. J. Prosthodont., 7, 1994, p.17.

13. TOTU, E. E., NECHIFOR, A. C., NECHIFOR, G., ABOUL-ENEIN, H. Y., CRISTACHE, C. M., J. Dent., 59, 2017, p. 68.

14. TOTU, E. E., CRISTACHE, C. M., ISILDAK, I., YILDIRIM, R., BURLIBASA, M., NIGDE, M., BURLIBASA, L., Rev. Chim.(Bucharest), 69, no.5, 2018, p.1160.

15. TOTU, E. E., CRISTACHE, C. M., Rev. Chim. (Bucharest), 68, no.9, 2017, p.2102.

16. TOTU, E. E., VOICILA, E., PISTRITU, V., NECHIFOR, G., CRISTACHE, C. M., Rev. Chim.(Bucharest), 69, no.1, 2018, p. 155.

17. TOTU, E. E., CRISTACHE, C. M., ISILDAK, S., TAVUKCUOGLU, O., PANTAZI, A., ENACHESCU, M., BUGA, R., BURLIBASA, M., TOTU, T., Mat. Plast., 55, no.4, 2018, p.616.

18. TOTU, E. E., CRISTACHE, C. M., VOICILA, E., OPREA, O., AGIR, I., TAVUKCUOGLU, O., DIDILESCU, A. C., Mat. Plast., 54, no. 4, 2017, p.666.

19. MCGARRY, T. J., NIMMO, A., SKIBA, J. F., AHLSTROM, R. H., SMITH, C. R., KOUMJIAN, J. H., GUICHET, G. N., J. Prosthodont., 13, no.2, 2004, p.73.

20. KAPUR, K. K., J. Prosthet. Dent., 18, 1967, p.550.

21. OLSHAN, A. M., ROSS, N. M., MANKODI, S., MELITA, S., Am. J. Dent., 5, no.2 1992, p.88.

22. PANTAZI, A., TOTU, E. E., DOROBANTU, D., CRISTACHE, C. M., ENACHESCU, M., Mat.. Plast., 55, no.4, 2018, p.634.

23. TOTU, E. E., RUSE, E., GARDEA, R., GRIGORESCU, A., Optoelectron. Adv. Mater., 2, 2008, p.442.

24. TOTU, E., SEGAL, E., COVINGTON, A. K., J. Therm. Anal. Calorim., 52, 1998, p.383.

25. TOTU, E., RUSE, E., LUCA, C., Rev. Chim.(Bucharest), 51, 2000, p.331.

26. CRISTACHE, C., M., IONESCU, C., BURLIBASA, M., CRISTACHE, G., ILIESCU, A. A., DUMITRIU, H., T., Metal. Int. 14, (SPEC. ISS.16), 2009, p.59.

27. CRISTACHE, C., M., IONESCU, C., CRISTACHE, G., IONESCU, I., ILIESCU, A., A., BURLIBASA, M., Metal. Int. 14, (SPEC. ISS.16), 2009, p.27.

28. FEINE, J. S., CARLSSON, G. E., AWAD, M. A., CHEHADE, A., DUNCAN, W. J., GIZANI, S., HEAD, T., LUND, J. P., MACENTEE, M., MERICSKESTERN, R., Int. J. Prosthodont., 15, 2002, p.413.

29. HWANG, H. J., LEE, S. J., PARK, E. J., YOON, H. I., J. Prosthet. Dent., 121, no.1, 2018, p.110.

30. CRISTACHE, C., OANCEA, L., DIDILESCU, A., BURLIBASA, M., TOTU, E., Rev. Chim.(Bucharest), 69, no.2, 2018, p.463.

$\overline{\text { Manuscript received: } 5.11 .2018}$ 